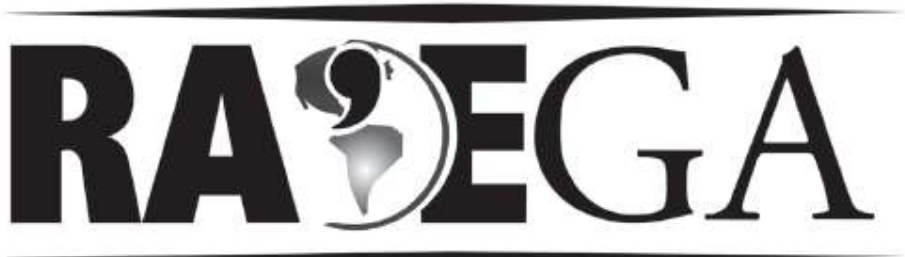

O ESPAÇO GEOGRÁFICO EM ANÁLISE

\title{
ZONEAMENTO AMBIENTAL DAS ÁREAS URBANA E DE EXPANSÃO URBANA DE CALDAS NOVAS (GO): UMA CONTRIBUIÇÃO METODOLÓGICA
}

\section{ENVIRONMENTAL ZONING OF URBAN AREAS AND URBAN EXPANSION OF CALDAS NOVAS (GO): A CONTRIBUTION METHODOLOGY}

\author{
Rildo Aparecido Costa ${ }^{1}$ \\ Luiz Nishiyama ${ }^{2}$
}

\section{RESUMO}

Este trabalho objetivou elaborar um mapa de zoneamento ambiental (1:25.000) das áreas urbana e de expansão urbana da cidade de Caldas Novas (GO), localizada no Sul Goiano, mais especificamente na Microrregião Meia Ponte. Esta cidade conheceu nas últimas três décadas um crescimento acelerado e praticamente sem nenhum planejamento, principalmente em relação ao meio físico. Para tanto utilizou-se a metodologia proposta por Costa (2008), onde foi utilizado três atributos do meio físico: Nível da Água Freática, Espessura dos Materiais Inconsolidados e Declividade. Através da sobreposição desses atributos foi possível definir seis classes para subsidiar o uso e ocupação local. Observou-se, que a cidade de Caldas Novas possui um crescimento totalmente desordenado e sem levar em conta os aspectos do meio físico. Com isso gerou-se uma série de problemas ambientais tais como: esgoto jogado a céu aberto, acomodação dos resíduos sólidos em lugares inadequados, além do surgimento de processos erosivos devido a um mau uso e ocupação do espaço urbano.

Palavras-Chave: Zoneamento Ambiental; Meio Físico; Urbanização; Planejamento Ambiental.

\footnotetext{
${ }^{1}$ Professor do Curso de Geografia da Faculdade de Ciências Integradas do Pontal da Universidade Federal de Uberlândia. e-mail: rildocosta@pontal.ufu.br

${ }^{2}$ Professor do Instituto de Geografia da Universidade Federal de Uberlândia. e-mail: nishi@ufu.br
} 


\section{ABSTRACT}

This study aimed to develop an environmental zoning map $(1: 25,000)$ from urban and urban sprawl of the city of Caldas Novas (GO), located on South State, specifically in the Meia Ponte microregion. This town has known three decades accelerated growth and virtually no planning, especially regarding the physical environment. For this we used the methodology proposed by Costa (2008), which was used three attributes of the physical environment: Level of water table, thickness of the unconsolidated material and Slope. By overlaying these attributes could define six classes to subsidize the use and occupation site. It was observed that the city of Caldas Novas is a totally uncontrolled growth and without taking into account aspects of the environment. With this generated a series of environmental problems such as sewage thrown open, accommodation of solid waste in inappropriate places, and the emergence of erosion due to poor use and occupation of urban space.

Keywords: Environmental Zoning; Physical Environment; Urban; Planning Environment.

\section{INTRODUÇÃO}

O desenvolvimento do processo tecnológico-industrial vem, nos últimos 50 anos, promovendo o crescimento dos centros urbanos. Nesse momento o homem, ao invés de se adaptar às condições do meio físico, impõe-lhe as suas próprias condições, fazendo com que, muitas vezes, o seu uso e ocupação se façam de maneira inadequada, ou seja, não respeitando os seus limites e potencialidades.

Se o uso e ocupação do meio físico é tão importante para o homem, este deve respeitá-lo e entendê-lo como um todo, principalmente quanto às suas potencialidades e limitações, pois o homem, ao ignorar esta condição, pode torná-lo vulnerável a danos até mesmo irreparáveis. Nesse sentido, tornase de suma importância o desenvolvimento da conscientização da coletividade, que passa a exercer papel fundamental no processo de uso e ocupação. Assim sendo, deve-se sempre se sobrepor a esse processo ações de preservação do meio, ainda que sua exploração seja necessária (COSTA, 2008).

Com o conhecimento científico-tecnológico que o homem adquiriu ao longo do tempo, é de se esperar que a ocupação realizada de maneira inadequada se torne cada vez menor. No entanto, o que se tem assistido, principalmente nos países em desenvolvimento, é que o caminho está sendo 
feito no sentido contrário, levando a impactos negativos que geralmente resultam em perdas materiais e até mesmo de vidas humanas. Por isso, a necessidade de planejar o uso e ocupação desse meio físico torna-se fundamental para qualquer instância, seja ela pública e/ou privada.

Nas áreas urbanizadas, o processo de uso e ocupação do meio físico é bastante diferenciado, dependendo do seu valor econômico. Assim, evidenciam-se os contrastes entre os bairros ricos e bairros pobres, a ocupação de áreas estáveis ou permissíveis para uso e, ao mesmo tempo, ocupação de áreas de risco (fundos de vales ou vertentes com declives acentuados). Deve-se salientar, também, que grandes incorporadoras transformam espaços considerados de risco em verdadeiras áreas propícias para a ocupação, o que demonstra a força do capital em relação às supostas limitações de uso impostas pelo meio físico.

Embora haja, nos dias atuais, grandes debates sobre meio ambiente, desenvolvimento e qualidade de vida, raramente se considera o princípio desses aspectos, que é o processo de planejamento. Entende-se que o ato de planejar seja a adoção de um conjunto de decisões baseadas em características técnicas do meio ambiente, nas necessidades da sociedade e nos fatores operacionais para uma dada região (Zuquette, 1993). Qualquer decisão de planejamento que considere informações parciais sobre o meio ambiente conduzirá a um desequilíbrio que implicará o aumento de custos, a diminuição de rendimentos e o esgotamento e destruição dos recursos naturais.

Os conhecimentos acerca dos componentes do meio físico (rocha, materiais inconsolidados, relevo, águas, ar e suas relações com os diferentes processos e atividades geológicos, biológicos e antropogênicos) fazem parte do campo de estudo das geociências. Essa afirmação é reforçada pelo fato de que todas as atividades antrópicas se desenvolvem sobre o meio físico (seus componentes) e são responsáveis pela sua sustentação (no sentido literal), quaisquer que sejam os tipos de ocupação (Turner; Coffman, 1973). Ao mesmo tempo, verifica-se uma relação de interdependência entre o meio físico e o meio biótico. 
Portanto, pode-se afirmar que o zoneamento ambiental, enquanto instrumento de representação dos atributos do meio físico, se torna um dos aspectos mais importantes para o planejamento.

$\mathrm{O}$ ato de se planejar um território corresponde a um conceito geográfico de regionalização, que significa individualizar o espaço em áreas que delimitam algum tipo de especificidade ou alguns aspectos comuns, ou áreas com certa homogeneidade. Sob uma perspectiva geográfica, o planejamento deve ser considerado como interação e intercâmbio de energia e matéria entre os componentes da paisagem, ou seja, essa homogeneidade se torna importante para se conhecer determinada área (BERTRAND, 1968).

Evidencia-se, então, a grande importância de se planejar um dado território visando otimizar a produção do espaço, seja ele urbano ou rural.

Segundo Sanchez e Silva (1995), planejar (planejamento da paisagem) é um ato em que se busca um desenvolvimento mais sustentado, envolve uma estratégia para melhorar e disciplinar as relações entre os aspectos geoecológicos e sócio-econômicos dos sistemas ambientais. Esse processo implica conceber e executar um projeto ambiental de recuperação, construção e manejo do território, assumindo o ambiente como um processo de transformações contínuas.

Trata-se de fazer do território um conjunto de paisagens estimulantes, benéficas e, por sua vez, capaz de conservar ou desenvolver uma identidade que expresse as necessidades e expectativas de sua gente. Isto significa projetar o território como um cenário múltiplo, compreendendo e valorizando a história, a realidade atual, potencialidades ecológicas e sócio-econômicas dos sistemas ambientais, nas quais se estrutura o território e se articula seu funcionamento global (PESCI, 1991).

O conceito de planejamento territorial surge na década de 1970, com a Carta Européia de Ordenamento do Território, devidamente associado ao Zoneamento Ecológico-Econômico, relacionado aos avanços tecnológicos, o que possibilitou um maior e mais detalhado conhecimento do meio físico e de sua utilização pelo homem. Esse conceito nasce juntamente às grandes discussões sobre o desenvolvimento sustentável (BECKER; EGLER, 1997). 
Segundo Sanchez e Silva (1995), não há planejamento sem um zoneamento geoambiental prévio que possibilite a integração interdisciplinar de todos os conhecimentos e percepções da diversidade do meio físico. O zoneamento geoambiental constitui um marco de referência estratégica para conceber o planejamento do território, tanto nas funções bióticas quanto abióticas.

Penteado Orellana (1976) evidenciou a importância do conhecimento do meio físico no planejamento, onde se tem um estudo voltado para o levantamento de problemas inerentes ao impacto causado pelo homem sobre 0 ambiente, no que diz respeito ao seu desejo de transformar o meio físico por meio do uso e ocupação. Ainda segundo a mesma autora, o planejamento possui dois aspectos básicos: planejar para preservar o meio ambiente e para usar racionalmente os recursos naturais, sem romper o equilíbrio do ecossistema; e tentar corrigir as falhas decorrentes da agressão sofrida pelo ambiente pela ação antrópica, em todos os seus aspectos.

Portanto, o mapeamento do meio físico é, hoje, indispensável para qualquer forma de planejamento do uso e ocupação do meio físico, pois por intermédio da espacialização dos atributos permite uma melhor compreensão da área a ser ocupada. Cabe ressaltar que o mapeamento utiliza conhecimentos gerais, ou seja, busca também conhecimento básico de outras ciências, como Hidrogeologia, Pedologia, Biologia e Geografia. Isso se deve a uma característica marcante: a multidisciplinaridade.

Evidencia-se, então, a grande importância de se conceder aos estudos de planejamento, um levantamento detalhado dos atributos do meio físico, visualizando, assim, os impactos ambientais e os custos de produção, pois o custo será bem menor ao se conhecer a área que vai ser ocupada, ou seja, planejar para depois ocupar. 


\section{MATERIAIS E MÉTODOS}

\subsection{METODOLOGIA}

Para o desenvolvimento do trabalho utilizou-se as cartas topográficas (1:25.000), elaboradas pelo DNPM - Departamento Nacional de Produção Mineral - Projeto Hidrogeológico da Região de Caldas Novas - GO, no ano de 1980. Para se obter o esboço da área estudada, usou-se a articulação das cartas SE-22 X-D-V 2 - SO; SE-22 X-D-V 2 - SE; SE-22 X-D-V 4 - NO e SE22 X-D-V 4 - NE.

Para a confecção do mapa de zoneamento ambiental utilizou-se três mapas básicos (utilizados apenas para confecção do mapa de zoneamento ambiental) que estão descritos a seguir.

a) Mapa de Declividade:

Para a confecção desse mapa utilizaram-se as cartas topográficas (mencionadas acima), com curvas de nível em eqüidistância de $20 \mathrm{~m}$, em escala de 1:25.000. As classes de declividade (0 - 2\%; 2 - 5\%; 5 - 10\%; $10-$ $20 \%$; 20 - 30\% e > 30\%) foram escolhidas no intuito de buscar uma maior precisão de dados, visando um planejamento mais detalhado. O software Arcgis 9.2 foi utilizado para a confecção da carta de declividade.

b) Mapa de Nível de Água Freática:

Para a obtenção do Mapa de Nível de Água Freática utilizaram-se medidas de cisternas contidas na área de estudo, perfazendo um total de 316 medidas, bem como a metodologia desenvolvida por Nishiyama (1998), que busca evidenciar, para uma análise mais precisa, meios alternativos para o levantamento da profundidade do nível d’água, tais como: mapas topográficos, fotografias aéreas pertencentes à USAF (Força Aérea dos Estados Unidos), obtidas em 1964 e 1965, em escala de 1:60.000, e também fotografias aéreas 
obtidas pela Prefeitura Municipal de Caldas Novas, no ano de 1993, na escala de 1:8.000 e imagens de satélite. Por meio desse material cartográfico foi possível analisar alguns condicionantes do meio físico (afloramento rochoso, áreas úmidas situadas em encostas, presença de nascentes e formas de relevo); junto aos dados obtidos nas medidas de cisternas, determinou-se a profundidade da Água Freática.

c) Mapa de Materiais Inconsolidados:

Foi obtido pela interpretação de fotografias aéreas pertencentes à USAF (Força Aérea dos Estados Unidos), obtidas em 1964 e 1965, em escala de 1:60.000 (utilizadas apenas para conferência das áreas), e também fotografias aéreas obtidas pela Prefeitura Municipal de Caldas Novas, no ano de 1993, na escala de 1:8.000.

Usaram-se, também, levantamentos de campo, tais como afloramentos rochosos, perfazendo um total de 28 amostras; utilizaram-se dados obtidos por sondagens de simples reconhecimento SPT, realizados pela empresa SETEF Serviços Técnicos de Fundações LTDA, perfazendo um total de 14 ensaios e dados obtidos das perfurações dos poços tubulares (para obtenção de água quente), em toda a área estudada, perfazendo um total de 57 amostras. Foram extraídas, também, 30 amostras deformadas na área de estudo, levadas para laboratório no intuito de caracterizar os materiais inconsolidados, segundo Zuquette (1987), seguindo estritamente as normas da ABNT - Associação Brasileira de Normas Técnicas.

Através desses três mapas foi confeccionado um mapa de Zoneamento Ambiental (Por intermédio do software Arcgis 9.2 foram sobrepostos os referidos mapas e utilizada a metodologia de álgebra de mapas) para Ordenamento do Uso e Ocupação Local, que tem como objetivo principal fornecer subsídio aos órgãos de planejamento e planejadores em geral. Essa metodologia (Costa, 2008) forneceu seis classes: Áreas Urbanizáveis, Áreas Urbanizáveis com Baixa Restrição, Áreas Urbanizáveis com Média Restrição, 
Áreas Urbanizáveis com Alta Restrição, Áreas Não Urbanizáveis e Áreas de Preservação

\subsection{CARACTERIZAÇÃO DA ÁREA DE ESTUDO}

A área de estudo situa-se na mesorregião sul do Estado de Goiás, mais especificamente na microrregião Meia Ponte, entre os meridianos $48^{\circ} 27^{\prime}$ e $48^{\circ}$ $56^{\prime} \mathrm{W}$ e os paralelos $17^{\circ} 28^{\prime}$ e $18^{\circ} 05^{\prime} \mathrm{S}$, totalizando uma área de aproximadamente $400 \mathrm{~km}^{2}$ (figura 1), possui o maior manancial hidrotermal do mundo (explorado para fins turísticos). A cidade de Caldas Novas se localiza a $170 \mathrm{~km}$ da capital do Estado (Goiânia), sendo a principal via de acesso a GO213 e BR 153.

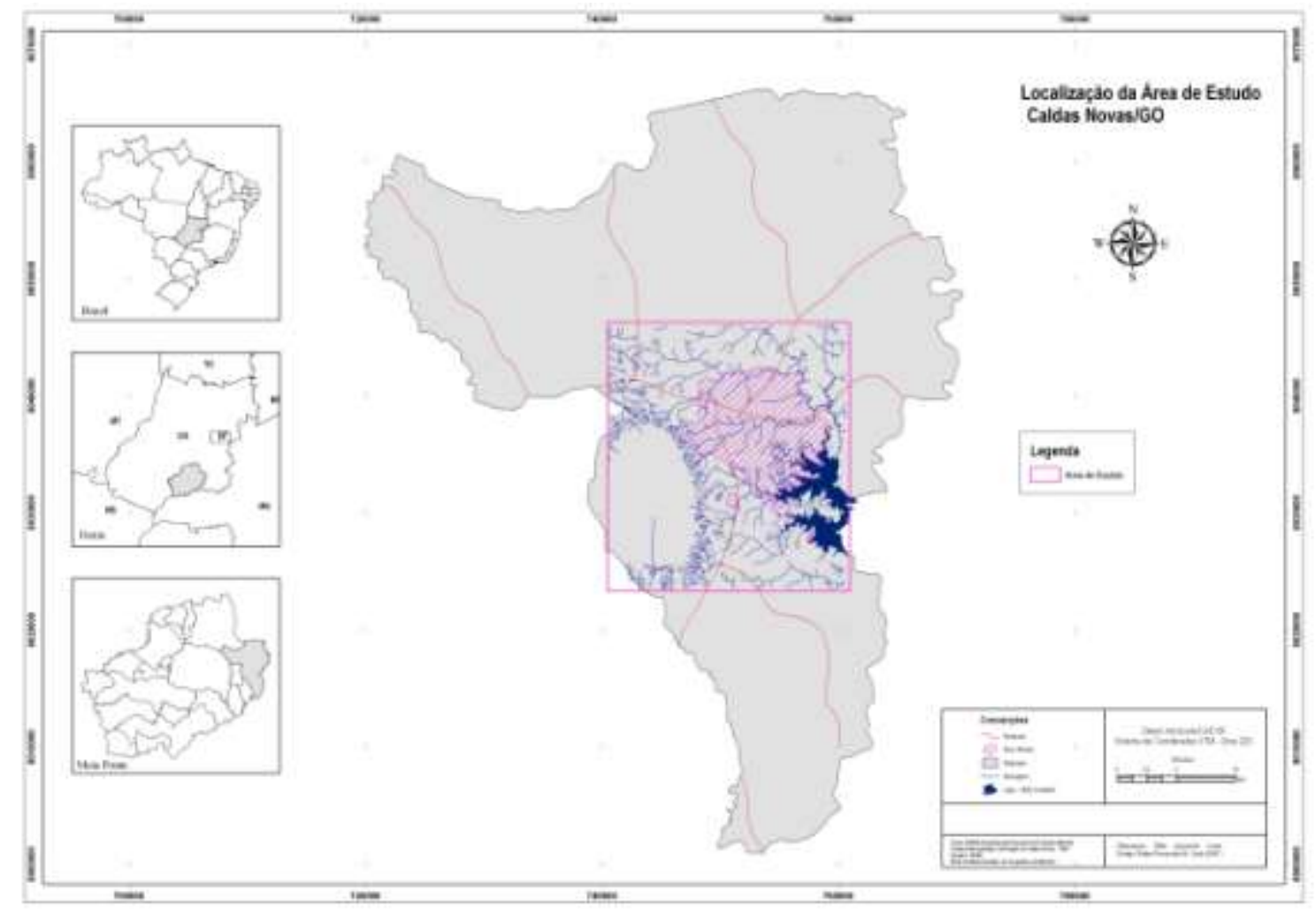

Figura - 1: Localização da área de estudo.

A dinâmica atmosférica, em Caldas Novas, está sob controle dos sistemas intertropicais. Esses sistemas de circulação ocasionam um clima tropical alternadamente seco e úmido (Del Grossi, 1991). Dependendo da 
época do ano, o avanço de determinadas massas de ar sobre a região é responsável pelas alterações na temperatura e, principalmente, na umidade, desencadeando duas situações climáticas nitidamente diferentes: um período seco, que se estende de abril a setembro (representa $10 \%$ do total de chuvas), e outro, úmido e chuvoso, que vai de outubro a março (representando $90 \%$ do total pluviométrico). Em Caldas Novas, essa dinâmica provoca um regime pluvial que varia entre 1720 a $1750 \mathrm{~mm}$, determinado, principalmente pelo orografismo.

O Município de Caldas Novas apresenta temperatura média anual entre 20 e $22^{\circ} \mathrm{C}$, com média nos meses mais frios girando em torno de $18^{\circ} \mathrm{C}$. Com base na classificação internacional de Koeppen (1948), a região encontra-se caracterizada pelo clima tropical do tipo Aw.

Em relação à geologia, a área e constituída principalmente por rochas metamórficas do Grupo Paranoá (Filitos, Quartizitos e Metacalcários) e do Grupo Araxá (representado por Xistos variados e ocorrem também, cristas de quartzitos, quartzitos micáceos e quartzo xistos, caracterizando prováveis arenitos e arenitos impuros, interdigitados e intercalados aos pelitos).

Em relação à geomorfologia, a área de estudo insere-se na região que Pena (1976) denominou Planalto Central Goiano, constituído pela ampla área do conjunto dos contribuintes da margem direita do rio Paranaíba, entre outros os rios Corumbá, Meia Ponte, dos Bois e Turvo. A referida unidade geomorfológica constitui um vasto planalto, compartimentado em níveis topográficos distintos e com características próprias, porém ligados entre si. São as seguintes as suas subunidades: Planalto do Distrito Federal, Depressões Intermontanas, Planalto do Alto Tocantins-Paranaíba e Planalto Rebaixado de Goiânia. Essa condição de relevo faz com que Caldas Novas se localize em uma região depressiva, tendo a leste a Serra de Caldas Novas e a oeste a Serra da Matinha. Essas condições geoambientais determinam o regime hídrico do município, possuindo uma grande quantidade de nascentes (Serra de Caldas Novas e Serra da Matinha) e conseqüentemente uma grande quantidade de águas superficiais. 


\section{RESULTADOS E DISCUSSÕES}

\section{1 - EVOLUÇÃO URBANA DA CIDADE DE CALDAS NOVAS}

Ao longo do século $X X$, acentuou-se a importância das cidades na dinâmica da sociedade. Segundo Santos (1997, p.53), "a cidade é um elemento impulsionador do desenvolvimento e aperfeiçoamento das técnicas. Diga-se, então, que é a cidade lugar de ebulição permanente".

Na segunda metade do século $X X$, o dualismo sítio-posição leva a uma visão regionalista dos aspectos econômicos, que desvincularia o estudo da cidade do seu ambiente natural (Del Grossi, 1991). Observa-se, nessa época, uma sistematização mais acadêmico-científica do conhecimento das mudanças que o processo de urbanização causa no meio físico.

O processo de urbanização brasileira é um fenômeno que ocorreu recentemente. A urbanização deve ser entendida como um processo social e espacial no qual a população rural é levada a deixar o campo para morar na cidade (esse processo ocorre também das cidades menores para cidades maiores) e, nela, ter de enfrentar suas contradições. Palen (1975, p.11) diz que "a urbanização é, portanto um processo pelo qual regiões rurais se transformam em regiões urbanas".

A política urbana no Brasil é marcada por deficiências que engendram inúmeros problemas ambientais, sociais, culturais e econômicos. A falta de um planejamento favoreceu o crescimento urbano desordenado, proporcionando modelos de cidades em que a qualidade de vida deixa a desejar.

Em Caldas Novas (GO), uma cidade que se desenvolveu tendo como base econômica o turismo, em muitos aspectos isso não foi diferente. 0 crescimento vertiginoso das últimas décadas provocou uma série de impactos no ambiente da cidade. A cidade se alargou, principalmente a partir da década de 1980, sem uma legislação consistente que monitorasse a sua expansão, o que, entre outros fatores, fez com que hoje, no perímetro urbano, haja falta de áreas verdes, áreas de lazer públicas e, ainda, problemas de circulação de pessoas e veículos, em determinados setores, principalmente na alta 
temporada. Os recursos hídricos sofrem todos os colapsos decorrentes da falta de manejo sócio-ambiental.

Com o crescimento econômico, há um notável aumento da população. Em 1980 a população do município de Caldas Novas era de 9.800 habitantes e, no ano de 1991, evolui para 24.900 habitantes (IBGE, 2008), tendo um aumento aproximado de 154,1\%, em menos de onze anos (vide tabela 01 ). Esse crescimento ocorre também nos dez anos subseqüentes, passando de 24.900 habitantes, em 1991, para 49.652 habitantes, em 2001, um aumento de aproximadamente $100,3 \%$.

Tabela 01 - Caldas Novas: Evolução da População, 1960 - 2010

\begin{tabular}{l|l|l}
\hline ANO & NÚMERO DE HABITANTES & CRESCIMENTO PERCENTUAL \\
\hline 1960 & 5.200 & - \\
\hline 1970 & 7.200 & 38.5 \\
\hline 1980 & 9.800 & 36.1 \\
\hline 1991 & 24.900 & 154.1 \\
\hline 2001 & 49.652 & 100.3 \\
\hline 2007 & 62.204 & 28 \\
\hline 2010 & 70.463 & 11.7 \\
\hline
\end{tabular}

Fonte: IBGE, 2010.

Esse vertiginoso crescimento populacional está intimamente relacionado com o crescimento econômico. Nesse caso, com o advento do turismo, que atraiu para a cidade um número muito grande de migrantes, oriundos de várias partes do Brasil. Porém, o que mais se destaca é o Nordeste, seguido por Minas Gerais e Distrito Federal.

Observa-se que, durante o século XX, houve, em Caldas Novas, uma crescente abertura de loteamentos. Enquanto que, até a década de 1970, foram abertos 19 loteamentos, somente na década de 1980, quando as águas termais começam realmente a se firmar como turismo, foram 23 abertos mais do que em toda a existência de Caldas Novas. Na década de 1990 houve 35 loteamentos abertos e, na década de 2000, 49, mostrando um crescimento desordenado e avantajado do perímetro urbano de Caldas Novas.

Em Caldas Novas, constatou-se que a especulação imobiliária e consequentemente, a criação de loteamentos, muitas vezes de um dia para o outro, faz com que a urbanização não tenha parâmetros legais e que a 
intervenção antrópica, no meio físico, não consiga integrar os espaços naturais e espaços antropogênicos.

Por causa da atividade turística, a construção civil é o setor que mais emprega mão-de-obra. Esses fatores contribuíram para que o enorme contingente de emigrantes, principalmente do Nordeste, viessem em busca de trabalho e, com eles, se formassem os bairros periféricos do município, causando pressão sobre as áreas de preservação permanentes, como a ocupação irregular das margens dos córregos que atravessam a malha urbana, tendo o Lago Corumbá como destino final de todos os dejetos. Grande parte dos empreendimentos de turismo e lazer também se formou em zonas de preservação permanente, e isso tudo diminuiu a oferta de espaços verdes públicos, na cidade.

\subsection{PROPOSTA DE ZONEAMENTO COMO SUBSÍDIO AO PLANEJAMENTO} AMBIENTAL DA CIDADE DE CALDAS NOVAS - GO

Para uma melhor compreensão dos problemas ambientais enfrentados por Caldas Novas, hoje, e com o intuito de apontar alternativas para um desenvolvimento ordenado do meio físico, elaborou-se uma proposta de zoneamento ambiental (Figura 2) para a área urbana e de expansão urbana de Caldas Novas, levando-se em conta vários parâmetros quantitativos (declividade, espessura dos materiais inconsolidados e profundidade do nível freático), onde se procurou a articulação dos atributos do meio físico, a partir de sua evolução, associada aos processos antrópicos atuais.

\subsection{1 - ÁREAS URBANIZÁVEIS}

Essa unidade localiza-se na porção Norte e Noroeste da área em estudo. É representada por altitudes que variam de 640 a 800 metros, e predominância de um relevo suave. Ocupa preferencialmente a microbacia do Córrego Fundo, que se encontra orientado no sentido E/W, esculpido pelo 
processo de erosão, e reativada em suas cabeceiras, o que gera feições pouco abruptas e escalonadas, de diferentes dimensões.

A evolução dessa unidade, bem como de toda a área estudada, deve-se ao contínuo recuo da porção superior das vertentes, associadas aos vales dos rios Pirapitinga e Corumbá. Em decorrência da diferença de resistência ao intemperismo e erosão dos materiais do substrato rochoso, representados pelos micaxistos do Grupo Araxá, costata-se a presença de áreas mais elevadas, resultantes de erosão diferencial.

Possui como base rochosa, quartzos-xistos com gnaisses e mármores subordinados (na porção Noroeste), e clorita, quartzos-xistos (na porção norte), pertencentes ao Grupo Araxá. Encontram-se, também, materiais inconsolidados retrabalhados, de idade mesoproterozóica, com características texturais areno-argilosas, com presença de fragmentos angulosos de quartzo e pouca de mica.

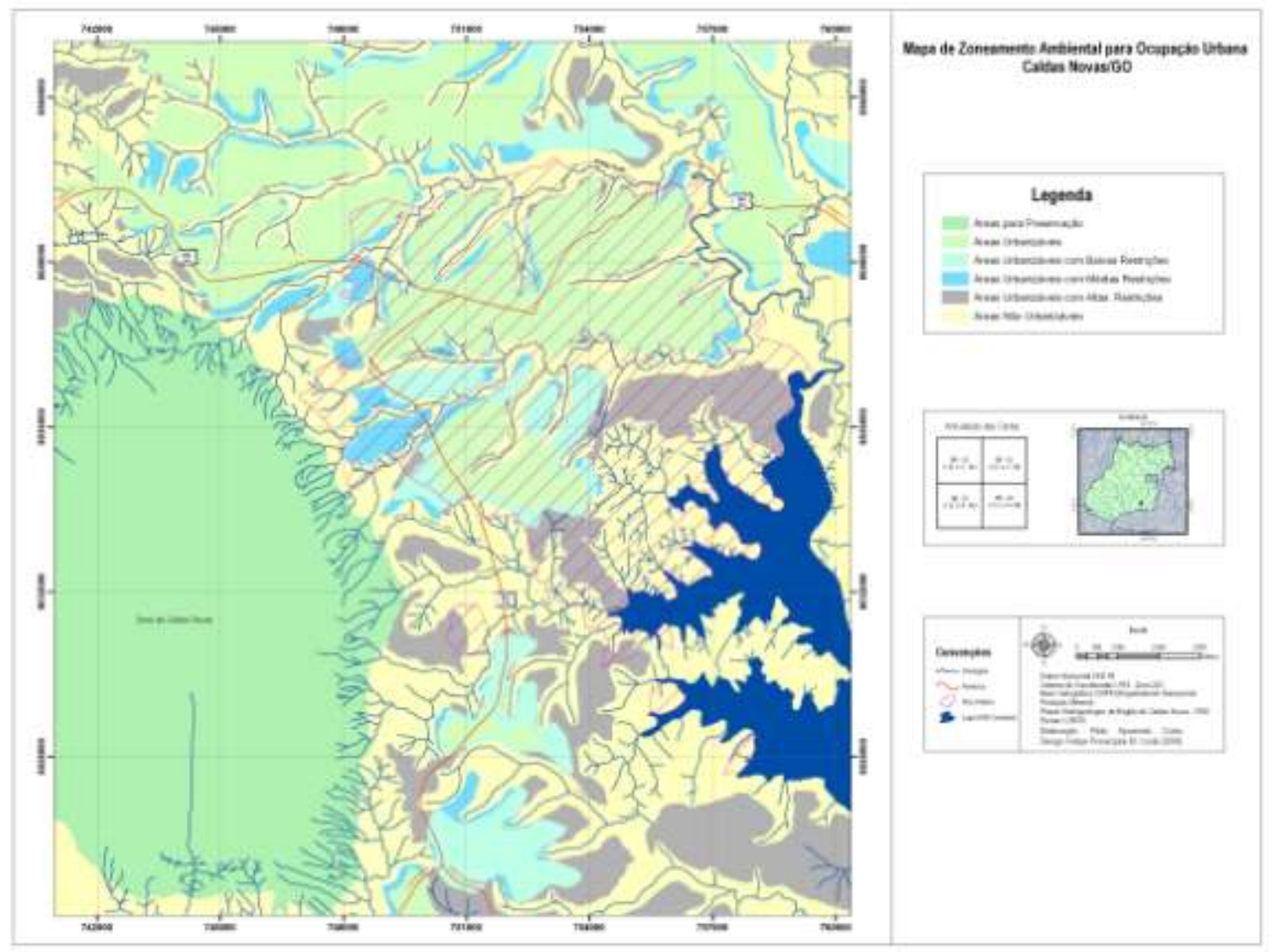

Figura - 2: Mapa de Zoneamento Ambiental de Caldas Novas 
A cobertura inconsolidada é constituída de materiais rudáceos, com presença de seixos e pedregulhos, retrabalhados, de textura areno-argilosa e coloração avermelhada (2.5 YR 7/4), entremeados de materiais siltosos originados do Micaxisto do Grupo Araxá, principalmente com a presença de seixos de quartzos e quartzitos. A espessura desse material inconsolidado está no intervalo de 2 a 10 metros.

Em relação à declividade, observa-se que esta unidade apresenta, em sua maior parte, valores inferiores a $2 \%$, principalmente nas áreas mais elevadas. As maiores declividades (2 a 5\%) apareceu somente nas vertentes do córrego Fundo e córrego Caldas.

Em relação à profundidade da água freática, pode-se chegar até a 12 metros, com oscilações mais abruptas quando o nível d’água encontra uma zona de falha, fazendo com que sua profundidade aumente.

Nessa unidade, o processo de urbanização ocorre de maneira mais intensa, principalmente entre o córrego Fundo e o ribeirão Caldas, onde se encontra ocupada em sua maior parte por edifícios de vários pavimentos. A ocupação da unidade é facilitada pelo modelado suavemente ondulado, desenvolvendo sobre um substrato rochoso constituído por material resultante da decomposição dos micaxistos do Grupo Araxá.

Porém, mesmo sendo uma das áreas mais favoráveis para o processo de urbanização, tem-se uma condição geoambiental frágil, associada a um uso e uma ocupação sem o mínimo de planejamento, o que possibilita a ocorrência de inúmeros impactos ambientais, dos quais se podem destacar:

\section{- Feições Erosivas}

Em relação às feições erosivas lineares, a cidade de Caldas Novas não possui grandes voçorocas, principalmente por causa do seu solo pouco espesso. Predominam os processos de ravinamento e sulcos, podendo ser encontrados em vários lugares da área de estudo, principalmente em bairros que não dispõem de rede pluvial. Porém, em locais onde os solos são mais profundos evidencia-se o aparecimento de voçorocas. 
A principal voçoroca localiza-se na porção nordeste do município (na área urbana). A recuperação dessa erosão é de suma importância, pois está se desenvolvendo em um local que pode vir a comprometer prédios, casas e até mesmo o empreendimento Clube Di Roma, que está localizado a montante da erosão. Recentemente, a própria Prefeitura Municipal de Caldas Novas destinou essa área para que os caminhões de entulho, principalmente rejeitos de construção civil, depositem seus resíduos.

É comum encontrar, também, erosões nas margens dos córregos, principalmente devido ao processo de desmatamento das matas ciliares que deixa o solo exposto, a mercê das águas pluviais.

Observa-se, nesse contexto, que os atributos do meio físico também favoreceram para que esses problemas ocorressem, pois nota-se que, praticamente, todos os problemas erosivos enfrentados pelo município de Caldas Novas estão relacionados com alguns fatores, característicos da região, tais como: materiais inconsolidados pouco espessos, Índices pluviométricos altos (para as áreas de cerrado) e, principalmente, por materiais rochosos impermeáveis (micaxistos do Grupo Araxá), aflorantes, fraturadas e falhadas.

- Deposição de Resíduos Sólidos

Caldas Novas, assim como a maioria das cidades do Brasil, ainda enfrenta o problema da falta de um tratamento de seus resíduos, como um todo. Esse processo, por aqui, possui um peso maior, visto que a economia local depende de um recurso hídrico subterrâneo e de um manejo adequado dos resíduos sólidos, cujo chorume está se infiltrando no solo e no subsolo, podendo contaminar águas subterrâneas, tanto a freática quanto a termal. Isso, com certeza, pode trazer conseqüências drásticas à economia do município, arruinando a demanda turística local.

Em Caldas Novas, diariamente, apenas uma fração do lixo domiciliar, comercial, público e hospitalar é recolhida por uma empresa privada, por meio de um serviço terceirizado (concessão), embora sob responsabilidade pública. Essa fração corresponde a 50 a $60 \%$ do total produzido na cidade, oriundos de 105 bairros, ficando fora do serviço de coleta os bairros periféricos. 
A fração restante, composta por resíduos sólidos ou não, orgânicos ou não, é disposta por seus geradores em locais e sob condições aleatórias, à revelia das autoridades municipais. Por exemplo, o denominado entulho, oriundo das construções civis, é coletado, mediante pagamento, por empresas, com grande eficiência e rapidez; porém, em seguida, é disposto, quase sempre sem nenhum critério, em áreas públicas e particulares menos visíveis, ou em depressões de terrenos na periferia urbana.

Uma circunstância que agrava ainda mais essa situação consiste no lixo domiciliar ou comercial, eventualmente recusado pelo serviço de coleta organizado como sendo perigoso, como os materiais para pintura (tintas, solventes, pigmentos e vernizes), produtos para jardinagem (pesticidas, inseticidas, repelentes e herbicidas), produtos para motores (óleos, lubrificantes, fluidos de freio e transmissão e baterias) e muitos outros itens mais comuns, como vidros, pilhas, pneus, lâmpadas fluorescentes, animais mortos, dentre outros. Estes são dispostos pelos seus geradores em locais menos visíveis do espaço urbano, normalmente em depressões de terrenos ou na margem de cursos d’água que cruzam a cidade.

O lixo hospitalar é recolhido à semelhança dos demais, embora a lei determine a coleta especial e a incineração em condições e locais apropriados, sendo os hospitais geradores igualmente responsáveis por esse serviço. 0 descarte hospitalar no lixão, por apresentar alta toxidade, constitui um fato de alto risco ambiental e para a saúde pública.

A fração coletada domiciliarmente é conduzida para o chamado "lixão" (que está localizado nessa unidade), onde é disposta em pilhas, podendo ser remexida por catadores à busca de objetos que possam vir a oferecer algum ganho, como plásticos e latas recicláveis. De tempo em tempo, o material das pilhas de lixo é revolvido por máquinas pesadas e espalhado e compactado na área.

O local do lixão de Caldas Novas situa-se a norte da cidade, na bacia do córrego Fundo, contribuinte do ribeirão Pirapitinga, em local situado em cotas altimétricas aproximadas de $730 \mathrm{~m}$, na zona de contato entre os micaxistos e os quartzitos do Grupo Araxá. Trata-se de uma área de alta vulnerabilidade devido 
ao elevado grau de fraturamento dos micaxistos e quartzitos e ao tipo de agente poluidor, que possui um potencial de alto risco ambiental.

O lixão existente está longe de ser o ideal, visto que a forma praticada de acondicionamento dos resíduos sólidos e do chorume não é a apropriada. $A$ localização do referido depósito é sobre falhas geológicas, em local com declive significativo, próxima a leitos d'água e com grande potencial contaminador.

\section{- Sistema de Coleta de Esgotos Sanitários}

A cidade possui, hoje, aproximadamente $25 \%$ de esgoto coletado e tratado, os quais se resume, praticamente, à área central. No restante da cidade, ainda se usa fossas. Segundo pesquisas diretas, Caldas Novas, possui aproximadamente 14.000 (quatorze mil) fossas, sendo estas, em sua maioria, fossas negras.

Há, ainda, um agravante, pois quase $60 \%$ da área urbana e de expansão apresentam um lençol freático que varia entre 0 e 5 metros de profundidade, o que limita o uso e a ocupação de extensas porções de terrenos. Esse fator - profundidade do lençol freático - se não forem tomadas as devidas precauções, pode gerar grandes impactos, principalmente poluição e contaminação da água subterrânea, pois um lençol muito raso, com uma grande quantidade de fossas, pode gerar vários problemas, inclusive de saúde (respiratórios e parasitoses).

Outro fator limitante é a espessura dos materiais inconsolidados que, em sua maioria, são pequenos. Esta situação causa problemas de ordem pública, tais como: contaminação por fossas, áreas de risco para atividades poluentes (postos de gasolina, lava-carros, hotéis, dentre outros).

Em suma, as deficiências de todo o sistema de esgoto sanitário existente em Caldas Novas, aliadas a um contexto geológico com fraturas profundas, de alta vulnerabilidade, configuram um panorama de alto risco para os aqüíferos subterrâneos.

No intuito de mitigar esses impactos, algumas ações são de suma importância, tais como: 
- determinar uma área especifica para o descarte dos resíduos oriundos dos materiais de construção e demolição;

- desenvolver um processo de reciclagem para esse material, haja visto que esse material possui um índice de reciclagem de até $80 \%$;

- proibir e conter a extração de cascalho, no perímetro urbano;

- desenvolver um projeto de recuperação de áreas que estão com processo degradação por essa extração ilegal;

- punir por meio de multas os responsáveis por essas ações de deposição indiscriminada.

\subsection{2 - ÁREAS URBANIZÁVEIS COM BAIXAS RESTRIÇÕES}

Esta unidade localiza-se por toda a área de estudo, sendo as suas maiores porções ao sul, na saída para a cidade de Uberlândia, e na microbacia do Ribeirão Caldas, abarcando uma das áreas mais urbanizadas. Representada por altitudes que variam de 700 a 800 metros, onde predomina um relevo suave ondulado. A utilização dessa unidade é também facilitada pelo modelado suave que se desenvolve sobre um substrato rochoso, constituído por material resultante da decomposição do micaxistos do Grupo Araxá.

Em relação ao seu embasamento rochoso, pode-se afirmar que a área localizada ao sul é composta por clorita, quartzos e xistos, e a região mais urbanizada, na microbacia do Ribeirão Caldas, é constituída de biotita, quartzo, xistos e quartzitos.

A cobertura inconsolidada é constituída de material areno-argiloso, com espessuras variando de 2 a 10 metros. É comum a presença de fragmentos angulosos de quartzos com pouca mica, coloração clara a avermelhada (2.5 YR 7/4).

Em relação à profundidade do nível da água freática, predomina 0 intervalo de 5 a 10 metros, apresentando-se oscilações mais abruptas quando o lençol encontra uma zona de falha, fazendo com que essa profundidade aumente, em relação ao restante da área. 
$\mathrm{Na}$ área mais central, localizada na microbacia do Ribeirão Caldas, é comum encontrar áreas com depósitos de lixo a céu aberto (entulhos, animais mortos, restos de jardinagem, etc.).

Essa situação contribui para o aparecimento de vetores de várias doenças. Encontra-se, também, uma grande concentração de fossas negras que, devido à pouca espessura do material inconsolidado, extravasam, contaminado os solos e as águas superficiais e subterrâneas, além do péssimo aspecto visual ao escoar livremente pelas ruas.

Outro grave problema é a Estação de Tratamento de Esgoto, que foi construída no local das antigas lagoas de estabilização de esgoto. Esta ETE está localizada dentro da área urbana, mais especificamente no bairro Parque Real. Praticamente, todos os gases e odores são lançados na atmosfera desse bairro. Existem, também, problemas de extravasamento do esgoto, por deficiência da capacidade de tratamento, o qual incide diretamente no Ribeirão Caldas.

Outrossim, ocorre a provável percolação de soluções ricas em nitrogênio, principalmente nitritos e nitratos, além de fósforo e metais pesados, com elevado potencial de contaminação por vírus e bactérias patogênicas, através de fraturas no maciço rochoso.

Ocorrem, também, problemas nas tubulações que levam o esgoto até a ETE, que sofrem rupturas freqüentes em alguns pontos aéreos, ocasionando a poluição de solos e, principalmente, dos mananciais de água.

A ação mais urgente a ser feita, nessa área é, sem dúvida, a instalação de rede de coleta de esgoto, com o intuito de eliminar as fossas negras, pois a facilidade de contaminação da água freática é notória, principalmente porque se sabe que o lençol freático está em contato com o aqüífero Araxá e, este em contato com o aqüífero Paranoá (termal) que é a base da economia do município de Caldas Novas.

Outra ação que deve ser tomada é o imediato fechamento das empresas que fazem a britagem do micaxisto ou, pelo menos, que se exija a regularização ambiental urgente, com fiscalização da deposição dos seus rejeitos. 
Em relação à Estação de Tratamento de Esgoto, esta deveria ser interditada, pois não oferece a menor condição de operação, por estar dentro de um bairro. Nos dias atuais, já existem técnicas adequadas para o tratamento de esgoto, tais como: impermeabilização das lagoas, queima do biogás ou seu reaproveitamento. Também se pode implantar, nessa área, um tratamento aeróbio, na tentativa de evitar vários problemas, tais como: maus odores, poluição dos solos, dentre outros. O processo aeróbio mais aplicado nos dias atuais é o lodo ativo (aeração prolongada).

\subsection{3 - ÁREAS URBANIZÁVEIS COM MÉDIAS RESTRIÇÕES}

Esta unidade encontra-se por toda a área de estudo (manchas), tendo uma maior concentração na porção centro-norte, representada por porções com altitudes que variam de 650 a 750 metros, onde se encontra um relevo suavemente ondulado.

Apresenta, na constituição do substrato rochoso, predominantemente a clorita, quartzo-xistos, e subordinadamente o quartzito. A declividade nas áreas de ocorrência da unidade é representada por valores entre 10 e 15\%, o que favorece a evolução de processos erosivos.

A cobertura inconsolidada é constituída de materiais retrabalhados de coloração avermelhada (2.5 YR 7/4), com textura areno-argilosa e espessuras predominantes dentro do intervalo de 2 a 5 metros, com a presença de fragmentos angulosos de quartzo.

Em relação à profundidade da água freática, predomina o intervalo de 5 a 10 metros, havendo oscilações mais abruptas quando o lençol encontra uma zona de falha.

Os principais impactos ambientais, nesta área, estão relacionados ao processo de erosão diferencial, que ocorre na ruptura de declive. Porém, como a área apresenta uma espessura inconsolidada pequena, formam-se apenas sulcos que eventualmente pode evoluir para ravinas. Além disso tem-se, aí, fossas negras, cujos efluentes vazam por toda a área de estudo.

Deve-se aplicar, nessa área, medidas corretivas, construindo-se rede pública de coleta de esgoto sanitário, na tentativa de evitar a contaminação dos 
lençóis de água, e preventivas, no sentido de evitar o desmatamento, nas bordas desse relevo.

\subsection{4 - ÁREAS URBANIZÁVEIS COM ALTAS RESTRIÇÕES}

Esta unidade localiza-se na porção centro-leste e sul (a maior porção) da área de estudo, representada por altitudes que variam de 600 a 700 metros, onde predomina um relevo mais dissecado, desenvolvendo-se sobre um substrato rochoso de biotita, quartzo-xistos, com um grau de intemperismo maior.

Em relação à sua declividade, pode-se encontrar, valores mais freqüentes no intervalo entre 15 e 20\%, favorecendo o escoamento superficial e a formação de sulcos.

A cobertura inconsolidada é constituída por materiais retrabalhados com textura areno-argilosa contendo seixos e pedregulhos de quartzo e quartzito e coloração avermelhada, com intercalações de materiais siltosos originados dos micaxistos do Grupo Araxá. A espessura desse material inconsolidado está no intervalo de 2 a 5 metros.

Em relação à profundidade da água freática, predomina o intervalo de 2 a 5 metros, podendo haver oscilações mais abruptas, quando o lençol freático encontra uma zona de falha.

O principal impacto ambiental encontrado nessa área está relacionado à disposição de efluentes domésticos em fossas negras em condições de pequena espessura dos materiais inconsolidados e baixa profundidade da água freática. É comum se observar esgoto a céu aberto devido ao extravasamento das fossas.

Deve ser construída, urgentemente, uma rede de captação de esgoto sanitário, na área da unidade, uma vez que esta apresenta severas restrições ao processo de uso e ocupação intensos, Os problemas ambientais são agravados com uma urbanização sem a menor preocupação com as condições limitantes do meio físico. 


\subsection{5 - ÁREAS NÃO URBANIZÁVEIS}

São encontradas em toda a área de estudo. São representadas principalmente pelos fundos de vale dos córregos. Apresenta como substrato rochoso os xistos do Grupo Araxá intercalados por quartzitos subordinados e declividades maiores do que $20 \%$.

A cobertura inconsolidada é constituída predominantemente de materiais retrabalhados de textura areno-argilosa e coloração avermelhada, entremeados de materiais siltosos originados do xisto do Grupo Araxá, principalmente com a presença de quartzos e quartzitos. A espessura desse material inconsolidado está no intervalo de 0 a 2 metros.

- Degradação dos Recursos Hídricos e o Uso e Ocupação das Áreas de Preservação Permanente

O grande problema é que isto não tem sido levado em consideração com nas áreas de nascentes consideradas urbanas, em Caldas Novas, já que várias dessas nascentes se encontram em desacordo com o que é estabelecido pelo Código Florestal de 1965 e, mais recentemente, em 2002, na Resolução 303 do CONAMA, os quais determinam preservação permanente para as florestas e demais formas de vegetação natural localizadas nas nascentes e nos chamados olhos d'água, qualquer que seja a situação topográfica, num raio mínimo de cinqüenta metros, de tal forma que proteja a bacia hidrográfica constituinte. Mais recente ainda, a Resolução CONAMA 369, de março de 2006, ratifica ser vedada à intervenção ou supressão de vegetação em APP (Área de Preservação Permanente) de nascentes e veredas.

Essa situação aponta a necessidade de recuperação e conservação dessas nascentes. A proteção das nascentes trabalha, principalmente, com a recuperação das matas ciliares, que são sistemas vegetais essenciais ao equilíbrio ambiental e, portanto, devem representar uma preocupação central para o desenvolvimento dito sustentável. A preservação e a recuperação das matas ciliares, aliadas às práticas de conservação e ao manejo adequado do 
solo, garantem a proteção daquele que é um dos principais recursos naturais: a água.

Observa-se que a ocupação irregular, ocorrida no processo de urbanização de Caldas Novas, trouxe enormes danos e prejuízos a essas áreas. Numa análise preliminar do curso d'água dos dois córregos (Ribeirão Caldas e Córrego do Açude) que atravessam a malha urbana do município, verificam-se inúmeras irregularidades quanto à sua preservação, o que evidencia a necessidade de um programa de recuperação ambiental para essas áreas. Escolheram-se esses cursos d'água pelo simples fato de constituirem duas bacias urbanas importantes e também as mais impactadas, por estarem dentro da área urbanizada.

\section{Córrego de Caldas}

O Córrego de Caldas nasce na porção oeste da cidade, recebendo a denominação de Córrego Saia Velha, ainda dentro do Parque Estadual da Serra de Caldas. Dentro do Parque, forma uma cachoeira com o nome Paredão. Logo nos seus primeiros metros após o parque, com uma densa mata ciliar, já começa a sofrer a ação do homem. Um loteamento de chácaras, no Setor Itanhangá II, simplesmente retalhou uma área verde, com lotes que chegam até as margens do córrego.

Na parte média do córrego tem seu inicio os empreendimentos turísticos formados por condomínios, hotéis e clubes. A forma de manejo desses empreendimentos é variada quanto ao córrego que atravessa seus domínios. Esse espaço público passa a compor, então, o domínio privado, sendo que essas margens ou foram incorporadas ao projeto arquitetônico e paisagístico das empresas turísticas ou foram completamente alteradas, para a construção de um shopping.

Todas essas apropriações do espaço público são ilegais, visto que, de acordo com as leis que regem a preservação das áreas verdes, todo leito de água, com menos de 10 metros, precisa de uma margem de preservação de 30 
metros, e a água é um bem de domínio público, como prevê a Lei nº 9.433 da Política Nacional de Recursos Hídricos.

\section{Córrego do Açude}

Sua nascente está localizada no Bairro Jardim Hanashiro, próxima do trevo sul de entrada da cidade, e do começo da Avenida Bento de Godoy; isso caracteriza sua condição urbana por excelência. Antes da influência antrópica, o córrego do Açude propiciou a formação de uma das fitofisionomias características do cerrado, as veredas; sendo os buritis (Mauritia flexuosa) a espécie mais freqüente. Nessa parte do leito do córrego do Açude, apesar de ser esta uma área classificada, no Plano Diretor Urbano, como Zona de Proteção Ambiental, pode-se verificar a existência de duas habitações que não respeitam os 30 metros de preservação.

Em menos de 200 metros de distância de suas nascentes, o odor característico de esgoto já se faz presente, denotando que o fator baixa densidade populacional das nascentes não é impedimento para os impactos ambientais ali se fazerem presentes. É possível observar, nos primeiros 500 metros desde a nascente do córrego, que uma grande área, com mais de 100 metros de extensão, a sua margem direita foi desmatada, mas, por estar ainda livre de construções, é passível de um projeto de recuperação.

\section{Lago Corumbá}

Com $65 \mathrm{~km}^{2}$ de área, o represamento do Rio Corumbá, para fins de produção de energia, proporcionou a formação de uma orla que, por lei e pelas dimensões do lago, deveria ter um mínimo de 100 metros de margens preservadas. No entanto, alheia à legislação ambiental, a especulação imobiliária, com o aval do poder municipal, promoveu a ocupação irregular de determinadas zonas nas margens do referido lago.

Segundo o Plano Diretor, essa área ocupada está dentro do perímetro urbano e recebe o nome de Zona de Expansão Turística.

De acordo com a lei de zoneamento urbano, ela deveria ter, inicialmente, o mínimo de 50 metros de margens de preservação. A legislação federal dita 
que, em zonas do perímetro urbano, é o município, e não a lei federal, que define os limites de preservação, observando-se, porém, o limite mínimo de 30 metros.

Vários impactos podem ser observados, principalmente, dentro da faixa dos 30 metros mínimos de preservação, quanto à ocupação e utilização das margens do Lago Corumbá. Uma vistoria, realizada pelo Ministério Público do Estado de Goiás (LTPA 032/2005 - PRC 14/05), na zona mais ocupada, tendo como ponto central a propriedade "Cavalo do Fogo", verificou a demarcação de loteamentos e diversas construções diretamente nas margens, desmatamentos, rede de energia elétrica, pastagens para gado, plantação de coqueiros e canavial, placas indicando venda de áreas, extração irregular de areia, esgotos lançados in natura, lixo urbano na foz do Córrego de Caldas e do Ribeirão Pirapitinga.

A elevada quantidade de bactérias e vírus patogênicos nas águas dos esgotos e fossas diversas, representam, verdadeiramente, um alto risco para a saúde e bem estar da população, ainda mais que, nas épocas de alta temporada turística, ocorrem picos de aumento de população, na casa de duas a três centenas de milhares de pessoas. Um sério problema reside em se saber a velocidade de migração das bactérias e vírus dentro de um sistema fraturado de águas subterrâneas, em um ambiente social com controles frouxos e ineficientes.

Um aspecto final, altamente negativo, da situação exposta, é o fato de que o destino de todo o esgoto de Caldas Novas ser o lago de UHE de Corumbá. A proliferação de loteamentos na orla do lago, sem exigências de serviços de esgotos sanitários, agrava o problema.

Nessa unidade (Lago Corumbá) dever-se-ia fazer a desapropriação dos empreendimentos (aplicação da legislação) localizados nas áreas de preservação permanente. Porém, sabe-se que isto é praticamente impossível, devido à influência política e poder econômico dos proprietários desses empreendimentos. A única alternativa para essas áreas são medidas compensatórias, que busquem amenizar ou, até mesmo, preservar outras 
áreas. Em relação às áreas doadas, poder-se-ia pedir a reintegração de posse, desde que seja feita a indenização das benfeitorias.

\subsection{6 - ÁREAS NÃO URBANIZÁVEIS - PRESERVAÇÃO}

Esta unidade localiza-se na porção sudoeste da área em estudo, correspondente ao domo estrutural (Serra de Caldas Novas). A área da unidade foi transformada em parque estadual, em 1990, definido então como uma área de proteção ambiental. As rochas presentes na área são de idade Neo/meso proterozóica, sendo seu embasamento rochoso constituído de quartzitos e metarenitos (topo da serra) e metarritmitos e metassiltitos (encostas) do Grupo Paranoá.

Em relação ao material inconsolidado, caracterizam-se como residuais de pequena espessura (encostas), sendo inferiores a $2 \mathrm{~m}$, e textura arenoargilosa. São comuns pedregulhos e seixos de quartzo e quartzito, de coloração vermelho amarelado, bege e acinzentado. No topo, prevalecem intervalos de espessuras 15 a 20 metros porém tendem para espessuras menores em direção à borda da Serra.

É representado por declividades baixas no topo da Serra (0 a 2\%), porém nas bordas da Serra de Caldas encontra-se as maiores declividades da área em estudo, atingindo valores compreendidos entre 20 e 40\%. Apresenta também, a profundidade do nível de água freática entre 10 e 15 metros.

$\mathrm{Na}$ porção do topo encontra-se um coeficiente de permeabilidade médio que varia de $3,1 \times 10^{-1}$ a $3,4 \times 10^{-3}$, facilitado pela capacidade de infiltração do solo (71\% de areia, $21 \%$ de argila e $8 \%$ de silte). Essa água, ao se infiltrar, percola de forma vertical até atingir os quartzitos e metarenitos, que são muito resistentes e impermeáveis. Ao atingir as rochas, o fluxo se torna horizontal, sendo responsável pelas nascentes nas bordas da Serra de Caldas, formando os córregos e ribeirões, que se dirigem para dentro da área urbana, como, por exemplo, Ribeirão Caldas, Córrego do Açude, Saia Velha, etc.

Os principais impactos existentes nessa área de unidade de conservação são as constantes queimadas e a intensa visitação, sem um plano 
de manejo adequado, principalmente por parte da Pousada do Rio Quente, o que, pode ocasionar problemas de desmoronamento e deslizamento.

Devido à grande importância hidrogeológica do domo estrutural de Caldas Novas e também ao fato de a principal fonte de renda da região estar baseada na exploração de água termal, torna-se extremamente importante a preservação das condições naturais da Serra de Caldas Novas, bem como o controle da ocupação desordenada do solo na porção do domo, evitando o constante aumento da área impermeabilizada. A impermeabilização pode vir a comprometer o futuro das reservas de águas termais, impedindo a recarga natural do sistema aqüífero, bem como o aumento do volume de águas economicamente exploráveis, pela mistura de águas entre os sistemas aqüífero (Paranoá termal/Araxá).

\section{CONSIDERAÇÕES FINAIS}

A análise integrada dos componentes do meio físico do município de Caldas Novas permitiu uma tentativa de estruturação da paisagem como subsídio ao planejamento. O município de Caldas Novas, situado entre os rios Corumbá e Piracanjuba e mais especificamente entre as Serras de Caldas Novas e Matinha, faz parte dos Dobramentos e Cavalgamentos Brasília, cujos principais aspectos morfológicos estão representados por uma depressão (depressão de Caldas Novas). A situação geográfica dessa área, localizada no setor periférico do Dobramento Brasília, determinou suas características estruturais, vinculadas tanto ao embasamento pré-cambriano como à história geológico-evolutiva.

Essas características estruturais, aliada aos demais atributos do meio físico que compõem a paisagem, identifica, de maneira geral, que o processo de uso e ocupação deu-se sem observar as limitações impostas pelo meio físico.

O uso e ocupação da cidade de Caldas Novas, foi realmente ocupado desordenadamente, observa-se que não se levou em conta a fragilidade do meio físico, ou seja, o planejamento não está sendo feito de maneira 
satisfatória, e a degradação ambiental é visível, gerando inclusive, prejuízos para o setor público-privado.

Observou-se, também, que os impactos ambientais de Caldas Novas, são gerados, em sua maioria, pela forma de uso e ocupação adotada pelo município. Embora temos que ressaltar também a fragilidade dos atributos do meio físico.

Os principais problemas apresentados na área dizem respeito aos riscos de contaminações da água freática, devido principalmente à pouca espessura dos materiais inconsolidados, um relevo de forma depressiva e a pouca profundidade dos lençóis freáticos guiados principalmente pela estrutura rochosa.

Recomenda-se, portanto, a adoção de medidas que evitem o intenso uso de fossas, no entanto, áreas já ocupadas e que possuem fossas é necessário que se aplique medidas corretivas, tais como:

- desenvolvimento de uma rede de coleta de esgoto, impermeabilização de fossas, caso não se tenha a rede de esgoto e água encanada.

- implantação de um sistema de monitoramento de contaminação do lençol freático;

- Mapeamento mais detalhado dos bairros possuidores do lençol freático superficial e captação de esgoto por fossas;

- esclarecer a comunidade sobre o risco de contaminação da água por esgoto.

Para as finalidades do presente estudo, é importante entender o fato de que as águas subterrâneas, principal fonte de geração de riquezas da cidade, configuram um sistema complexo e de difícil caracterização, e sua exploração se dá em áreas urbanas densamente povoadas. Tem sido quase nula a preocupação do poder público e da sociedade em geral com relação às inúmeras agressões ao recurso hidrotermal e ambiental que são perpetradas, constantemente, inconscientes da lei de ação e reação da natureza. Assim, a situação de risco é considerável.

Por fim, o zoneamento e suas correlações qualitativas gerados neste trabalho, por apresentarem as características do meio físico, podem ser 
utilizados no auxilio ao planejamento urbano, principalmente no melhoramento do Plano Diretor Urbano, visando à adequada ocupação desse meio físico, levando-se em conta suas potencialidades e restrições.

\section{REFERÊNCIAS}

BARBOSA, D. L. Um olhar sobre o Estatuto da Cidade enquanto instrumento de reforma urbana: um estudo sobre a elaboração $e$ implementação do Plano Diretor em Caldas Novas. 2004. Dissertação (Mestrado em Desenvolvimento Econômico) - Universidade Federal de Uberlândia, Uberlândia, 2004.

BECKER B.; EGLER, C. Detalhamento da metodologia para execução do Zoneamento Ecológico-econômico pelos Estados da Amazônia Legal. Rio de Janeiro/Brasília: SAE-MMA, 1997.

BERTRAND, G. Paisagem e Geografia Física Global. Caderno de Ciências da Terra. São Paulo. (13): 1 - 27, 1968.

COSTA, R. Ap. Zoneamento Ambiental da Área de Expansão Urbana de Caldas Novas - GO: procedimentos e aplicações. 216 f. Tese (Doutorado em Geografia e Gestão do Território). Instituto de Geografia, UFU, Uberlândia, 2008.

DEL GROSSI, S. R. As características regionais da natureza. De Uberabinha a Uberlândia: os caminhos da natureza. 1991. Tese (Doutorado em Geografia) - Faculdade de Filosofia, Letras e Ciências Humanas, Universidade de São Paulo, São Paulo, 1991.

KOEPPEN, W. Climatología. México-Buenos Aires: Fondo de Cultura Económica, 1948.

NISHIYAMA, L. Procedimentos de Mapeamento Geotécnico com Base para análises e avaliações ambientais do meio físico em escala de 1:100.000 aplicação no município de Uberlândia - MG. 1998. Tese (Doutorado em Geotecnia) - Escola de Engenharia de São Calor, Universidade de São Paulo, São Carlos, 1998.

PALEN, J. J. O Mundo Urbano. São Paulo: Forense-Universitária, 1975.

PENA, G. S. Projeto Goiânia II. Relatório Final. Goiânia: DNPM/CPRM. 1976. $5 \mathrm{v}$.

PESCI, R. La Cultura del Território. Ambiente, La Plata, v. 11, n.68, ano XI, 1991. 
PENTEADO ORELLANA, M. M. A Geomorfologia no Planejamento do Meio Ambiente. Notícias Geomorfológicas, Campinas, v.16, n.31, p.3-15, 1976.

SANCHEZ, R. O.; SILVA. T. C. Zoneamento Ambiental: uma estratégia de ordenamento da paisagem. São Paulo: IBGE, 1995.

SANTOS, M. A Urbanização Brasileira. São Paulo: Hucitec, 1997.

TURNES, A. K.; COFFMAN, D. M. Geology of Planning: a review of environmental geology. Golden, v.68, 1973.

ZUQUETTE, L. V. Análise Crítica da Cartografia Geotécnica e Proposta Metodológica para Condições Brasileiras. 1987. Tese (Doutorado em Geotecnia) - Escola de Engenharia de São Carlos, Universidade de São Paulo, São Carlos, 1987.

. Importância do Mapeamento Geotécnico no Uso e Ocupação do Meio Físico: fundamentos e guia para elaboração. 1993. Tese (Livre Docência) - Escola de Engenharia de São Carlos, Universidade de São Paulo, São Carlos, 1993.

Recebido em 05/10/2011.

Aceito em 26/03/2012. 